\title{
Peri-implantitis Seeded by Permanent Cement - A Case Report from Karachi, Pakistan
}

\author{
Munis Mukhtar ${ }^{1 *}$, Zehra Tariq ${ }^{2}$ and Maaz Asaad ${ }^{3}$ \\ ${ }^{1}$ Oral Implantology (Germany), Diplomat International Congress of Oral \\ Implantologist) (USA), Karachi, Pakistan \\ ${ }^{2}$ Karachi, Pakistan \\ ${ }^{3}$ Assistant Professor, Department of Periodontology, Baqai Medical University, \\ Pakistan \\ *Corresponding Author: Munis Mukhtar, Director Academy of Orofacial \\ Aesthetics, Diplomat of International Congress of Oral Implantologist, Karachi, \\ Pakistan.
}

Received: October 22, 2020

Published: November 25, 2020

(C) All rights are reserved by Munis Mukhtar., et al.

\begin{abstract}
Peri-implantitis is a chronic complication affecting the soft and hard tissues surrounding the dental implant. The prevalence of peri-implantitis ranges from $21 \%$ on implant-level, and $34 \%$ on patient-level. Several treatment methods have been proposed that are aimed at arresting the disease and potentially regenerating bone defects related to it. Here, we report the case of a patient presented with cement induced peri-implantitis of moderate severity with thin, mobile soft tissue and a probing depth of $6 \mathrm{~mm}$ two years post-implant placement. A radiographic assessment revealed bone resorption of about $40 \%$ of the length of the implant. Mechanical and Chemical debridement, followed by hard and soft tissue grafting, was employed as a treatment modality for the successful resolution of peri-implantitis.
\end{abstract}

Keywords: Peri-implantitis; Cement Induced Peri-implantitis; Implantoplasty; Guided Bone Regeneration; Free Gingival Graft

\section{Introduction}

Peri-implantitis is a chronic complication affecting the soft and hard tissues surrounding the dental implant [1]. The prevalence of peri-implantitis ranges from $21 \%$ on implant-level, and $34 \%$ on patient-level [2]. The treatment of Peri-implantitis poses a serious problem that is faced by many clinicians today and there seems to be a lack of agreement on the management of Peri-implantitis that would provide the most successful outcome. Several treatment methods have been proposed that are aimed at arresting the disease and potentially regenerating bone defects related to it.

Peri-Implant complications can be classified into two main types:

- Peri-Implant Mucositis is characterized mainly by inflammation of the peri-implant soft tissue, bleeding on probing, and suppuration but without any radiographic evidence of bone loss.
- Peri-implantitis which has all the characteristic signs of Mucositis as well as hard tissue involvement with progressive bone loss and eventual loss of Osseointegration [3].

Both of these diseases have an infectious nature and the Etiology of these complications appears to be bacterially originating from dental biofilms, the composition of which is similar but much more complex than Periodontitis [4]. The means used for the diagnosis of peri-implant conditions include Periodontal Probing and Dental Radiography [5]. A Classification has been proposed by Froum and Rosen [6] that allows us to differentiate Peri-implantitis based on the Probing depth and the extent of bone loss surrounding the implant. Three different stages of severity have been described:

- $\quad$ Early peri-implantitis shows a Probing depth of at least $4 \mathrm{~mm}$ and a bone loss of less than $25 \%$ of the total implant length as seen on radiographs. 
- $\quad$ Moderate peri-implantitis shows a Probing depth of at least $6 \mathrm{~mm}$ and radiographic bone loss of $25-50 \%$ of the total implant length.

- Advanced peri-implantitis is characterized by a probing depth of at least $8 \mathrm{~mm}$ and radiographic bone loss of more than $50 \%$ of the length of the implant.

Some of the risk factors for peri-implant complications include poor oral hygiene and history of periodontal disease [3]. Factors such as occlusal overload, [7] improper seating, or over contouring of the crown may also contribute to the development of Periimplantitis [8]. One of the major risk factors for peri-implantitis occurs because of the presence of residual cement surrounding the implant resulting in inflammation of the peri-implant tissue, bone loss as well as patient discomfort [9]. Cement-retained implantsupported crowns are immensely popular among practitioners as a means of replacing edentulous spaces because of their less demanding surgical placements, simple technique, and passive fit as compared to screw-retained ones. Their lower cost, improved aesthetics, and the elimination of screw loosening makes them a better choice for most patients as well [10]. However, the clinical problems associated with the inability to completely remove cement cannot be ignored. Residual cement, because of its rough surface can act as a reservoir for the growth of bacteria and its by-products similar to dental plaque leading to both soft and hard tissue complications [10]. In a recent study Residual cement was found to be the cause of peri-implantitis in $81 \%$ of the cemented cases with the resolution of disease in $74 \%$ after removal of the excess cement [11].

Most of the treatment options for Peri-implantitis are based on the methods used commonly for the treatment of Periodontitis because they are known to share a common microbial etiology [12]. The ideal treatment goal would be the elimination of inflammation and bleeding on probing [1], detoxification of the implant surface and ultimately the restoration of Osseointegration [13].

Chemical debridement followed by Implantoplasty - a procedure involving modification or smoothening of the surface of the implant [14] in combination with bone grafting and the use of membranes has been indicated for the treatment of peri-implantitis [15].

Here, we report the case of a patient who presented with cement induced peri-implantitis and has described in detail how perform- ing chemical and mechanical debridement followed by hard and soft tissue grafting resulting in complete resolution of the problem.

\section{Case Report}

A 21 year -year-old male patient presented to our clinic for his second annual follow- up appointment post-implant placement on tooth number 36 . While on a trip to his home-town his crown, which had been previously cemented using long term temporary cement (Dentotemp ${ }^{\circledR}$ ) had dislodged and he had gotten it re-seated. Upon examination of the peri-implant soft tissue site, it seemed as if the Crown was seated with permanent cement. On further examination, the soft tissue around the collar of the implant was found to be thin and mobile, with an increased pocket depth of 5 to $6 \mathrm{~mm}$ in addition to bleeding and tenderness on probing (Figure 1). Radiographic investigation showed a Crater like bone resorption around the implant with bone loss extending to about $40 \%$ of the total length of the implant (Figure 2). A diagnosis of Cement induced peri-implantitis of moderate severity was made [6]. A treatment plan for chemical debridement followed by Implantoplasy with hard and soft tissue grafting to reduce the pocket depth and to stabilize the soft tissue was devised.

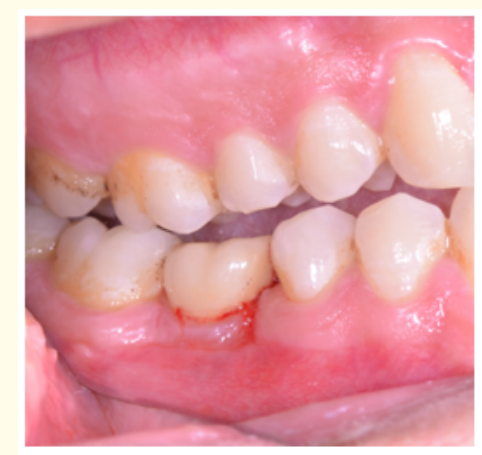

Figure 1

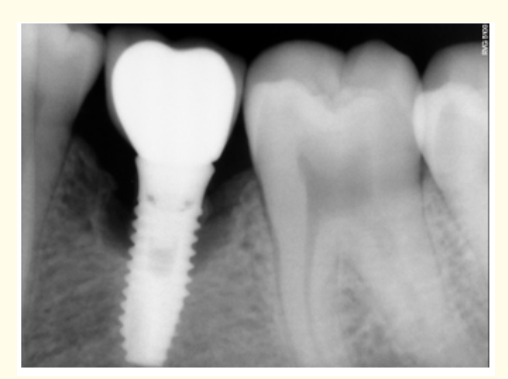

Figure 2 


\section{Treatment}

A full-thickness Muco-periosteal flap was raised to expose the defect and the probing depth was confirmed (Figure 3). The area was cleaned first with the help of a plastic curette then with saline dipped gauze followed by a normal saline wash [16]. Chemical debridement using a $0.12 \%$ Chlorhexidine solution was done [17]. Implantoplasty was performed up until the last threads of the implant that were exposed by the defect, first with the help of a fine finishing round bur and then, by the use of a polishing bur (Figure 4). The area was again rinsed with Saline to remove titanium dust particles or any other contaminants and irrigated with doxycycline solution. A connective tissue graft, taken from the patient's palate (Figure 5) was attached to the buccal flap with the help of sutures (Figure 6).

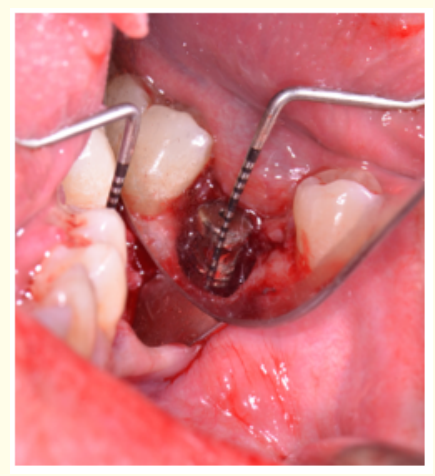

Figure 3

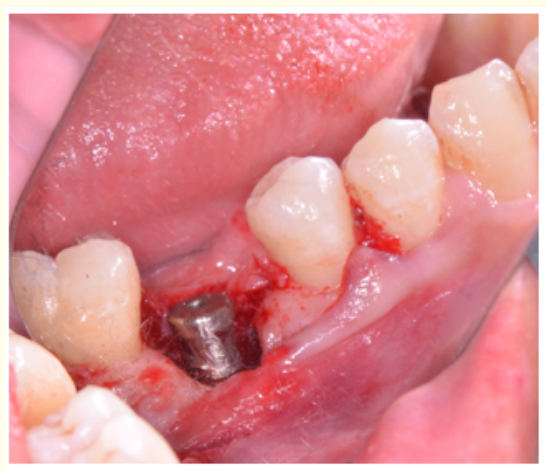

Figure 4

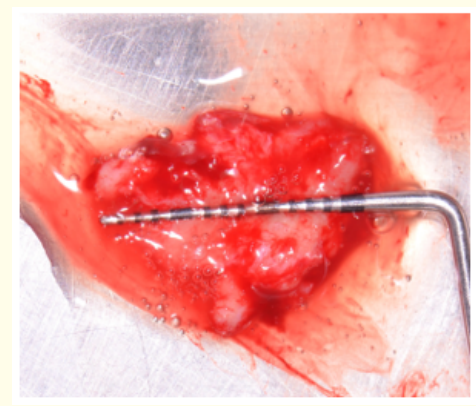

Figure 5

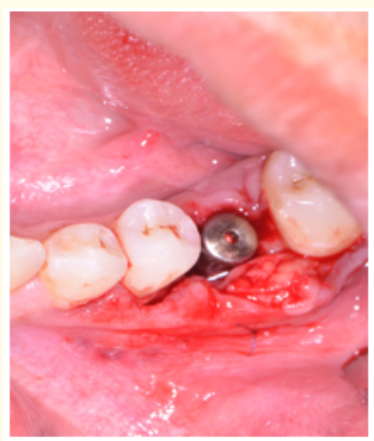

Figure 6

A sticky bone containing Cortical bone powder (SureOSS ${ }^{\varpi}$ ) Allograft, Alloplast (Beta-Tricalcium Phosphate particles), and Concentrated liquid growth factors in the form of IPRF, (Injectable Platelet-rich Fibrin) was properly packed all around the defect. The bone was concealed with alloderm acting as a GTR (Guided tissue regeneration) membrane (Figure 7). The Alloderm was further covered with a PRF (Platelet-rich Fibrin) membrane and Primary closure was achieved using Cytoplast PTFE sutures (Figure 8).

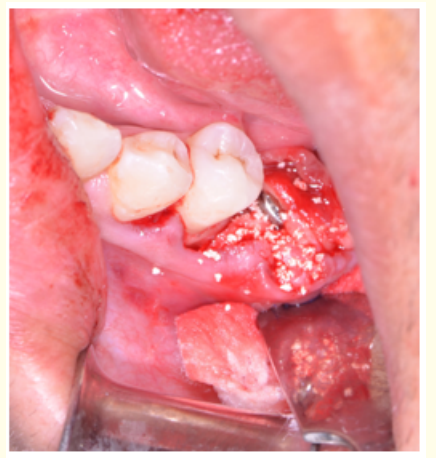

Figure 7 


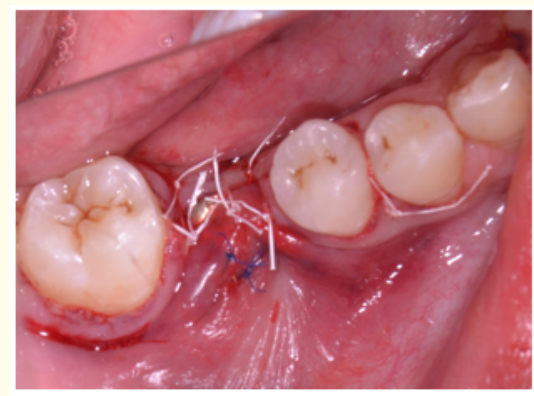

Figure 8

After 10 days of uneventful healing, the sutures were removed and after 8 weeks the probing depth was noted to be reduced to only $2 \mathrm{~mm}$ (Figure 9). The tissue around the graft was still found to be mobile so a Free Gingival Graft (FGG) was planned to achieve a stable Keratinized tissue around the collar of the implant. A partialthickness graft was taken from the palate (Figure 10). The mobile buccal flap was apically repositioned and Periosteum was exposed. The Free Gingival Graft was sutured to the exposed Periosteum (Figure 11). The graft was covered with Cyanoacrylate glue (Peri-

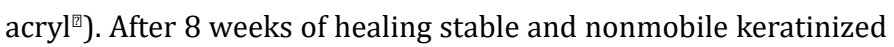
tissue was seen. The patient was provided with a screw-retained final prosthesis to prevent any such complications in the future (Figure 12). The Patient was recalled every three months to assess treatment success.

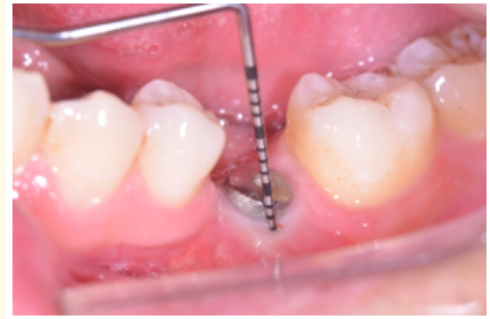

Figure 9

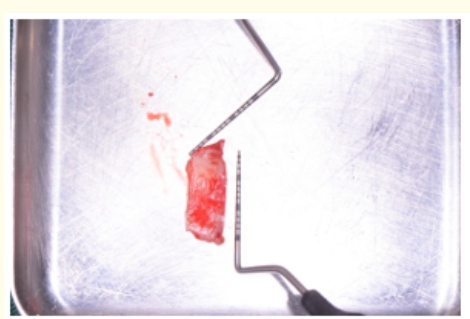

Figure 10

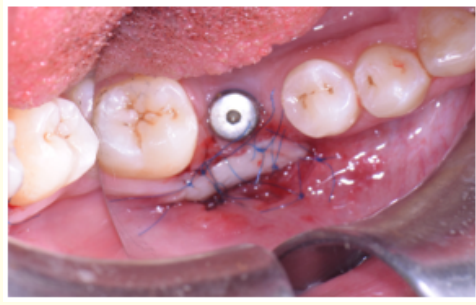

Figure 11

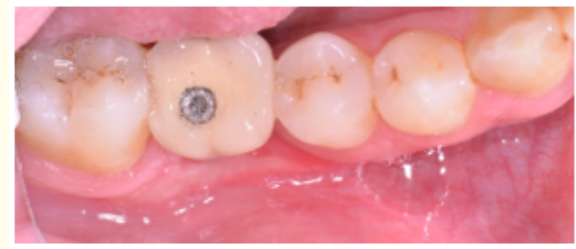

Figure 12

At one year follow-up, the patient had maintained oral hygiene levels. The implant and prosthesis were in the desired position and ideal bone levels were viewed on radiographs (Figure 13). Pocket depths were satisfactory (Figure 14) and no bleeding on probing was observed. The implant and crown were functioning adequately.

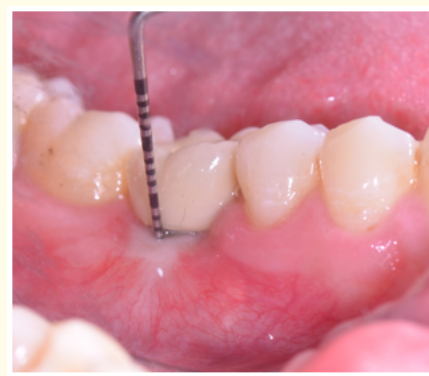

Figure 13

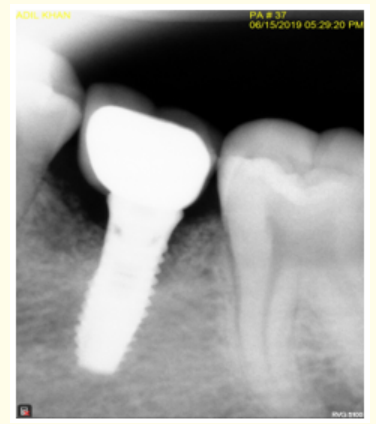

Figure 14 


\section{Discussion}

Many clinicians may come face to face with Peri-implant complications and hesitate to perform treatment interventions because of uncertain prognosis. The search for a predictable treatment strategy for peri-implantitis is ongoing.

In this case report we have described how chemical and mechanical debridement in combination with hard and soft tissue graft and the use of barrier membranes has led to successful treatment of periimplantitis and stability of the implant. However, this treatment modality has certain limitations and cannot always be applied. Implantoplasty tends to reduce the diameter and appears to decrease the strength of implants making it weak and more prone to fracture. It is therefore crucial that this procedure is performed with caution on narrow implants that may be subject to higher occlusal forces [18]. Another condition would be when severe peri-implantitis has occurred which has led to a loss of more than $60 \%$ of the implant to bone contact and mobility of implant is seen. In such cases, removal of the implant is the only option [19].

The damage caused by inadequate removal of cement is seen in this particular case. It is clear that these effects could have simply been avoided had careful and thorough attempts at cement removal been employed at the time of cementation. Close clinical monitoring and regular follow-up after cementation can help avoid irreversible damage as early detection and immediate therapy can lead to maximum therapeutic benefits. Alternatively, the use of a screw-retained crown instead of a cemented one may be beneficial.

\section{Conclusion}

This case report is a vivid reminder of the destructive effects that can occur as a result of inadequate removal of cement from around the implant and neglect at the part of the clinician. The results from this Case report suggest that moderate peri-implantitis caused by residual cement can be successfully treated using chemical and mechanical debridement in combination with hard and soft tissue grafting. It sheds light on the need to follow a proper cementation protocol which, combined with regular monitoring can easily prevent the development of peri-implantitis.

\section{Bibliography}

1. Novaes Junior., et al. "New strategies and developments for peri-implant disease". Brazilian Oral Research 33 (2019).

2. Kordbacheh Changi., et al. "Peri-implantitis prevalence, incidence rate, and risk factors: A study of electronic health records at a US dental school". Clinical Oral Implants Research 30.4 (2019).
3. Schwarz Frank., et al. "Surgical regenerative treatment of periimplantitis lesions using a nanocrystalline hydroxyapatite or a natural bone mineral in combination with a collagen membrane: a four-year clinical follow-up report". Journal of Clinical Periodontology 36.9 (2009): 807-814.

4. Romanos Georgios E., et al. "Long-term evaluation of immediately loaded implants in the edentulous mandible using fixed bridges and platform shifting". Clinical Implant Dentistry and Related Research 16.4 (2014): 601-608.

5. Berglundh Tord., et al. "Peri-implant diseases and conditions: Consensus report of workgroup 4 of the 2017 World Workshop on the Classification of Periodontal and Peri-Implant Diseases and Conditions". Journal of Periodontology 89 (2018): S313-S318.

6. Froum Stuart J and Paul S Rosen. "A proposed classification for peri-implantitis". International Journal of Periodontics and Restorative Dentistry 32.5 (2012).

7. Isidor Flemming. "Influence of forces on peri-implant bone". Clinical Oral Implants Research 17.S2 (2006): 8-18.

8. Kim Jong-Eun., et al. "A two-stage surgical approach to the treatment of severe peri-implant defect: a 30-month clinical follow-up report". Journal of Oral Implantology 40.3 (2014): 299-305.

9. Wadhwani Chandur., et al. "Radiographic detection and characteristic patterns of residual excess cement associated with cement-retained implant restorations: a clinical report". The Journal of Prosthetic Dentistry 107.3 (2012): 151-157.

10. Steven Present D M D. "Complications with excess cement \& dental implants: Diagnosis, recommendations and treatment of 7 clinical cases".

11. Wilson Jr and Thomas G. "The positive relationship between excess cement and peri-implant disease: a prospective clinical endoscopic study". Journal of Periodontology 80.9 (2009): 1388-1392.

12. Ericsson I., et al. "Long-standing plaque and gingivitis at implants and teeth in the dog". Clinical Oral Implants Research 3.3 (1992): 99-103.

13. Romanos Georgios E., et al. "Peri-implant diseases: a review of treatment interventions”. Dental Clinics 59.1 (2015): 157-178.

14. Romeo Eugenio., et al. "Therapy of peri-implantitis with resective surgery: A 3-year clinical trial on rough screw-shaped oral implants. Part I: clinical outcome". Clinical oral implants research 16.1 (2005): 9-18. 
15. Norowski Jr., et al. "Biomaterial and antibiotic strategies for peri-implantitis: A review". Journal of Biomedical Materials Research Part B: Applied Biomaterials: An Official Journal of The Society for Biomaterials, The Japanese Society for Biomaterials, and The Australian Society for Biomaterials and the Korean Society for Biomaterials 88.2 (2009): 530-543.

16. Schwarz Frank., et al. "Combined surgical therapy of peri-implantitis evaluating two methods of surface debridement and decontamination. A two-year clinical follow up report". Journal of Clinical Periodontology 39.8 (2012): 789-797.

17. Heo SunJin., et al. "Simplified nonsurgical treatment of periimplantitis using chlorhexidine and minocycline hydrochloride". Journal of Periodontal and Implant Science 48.5 (2018): 326-333.

18. Chan Hsun-Liang., et al. "Impact of implantoplasty on strength of the implant-abutment complex". International Journal of Oral and Maxillofacial Implants 28.6 (2013).

19. Lang Niklaus $P$ and Jan Lindhe eds. Clinical periodontology and implant dentistry, 2 Volume Set. John Wiley and Sons (2015).

\section{Assets from publication with us}

- Prompt Acknowledgement after receiving the article

- Thorough Double blinded peer review

- Rapid Publication

- Issue of Publication Certificate

- High visibility of your Published work

Website: www.actascientific.com/

Submit Article: www.actascientific.com/submission.php

Email us: editor@actascientific.com

Contact us: +919182824667 